\title{
Do mar ao sertão: a Estratégia Saúde da Família no Nordeste Brasileiro
}

Este número temático da Ciência \& Saúde Coletiva versa sobre a Estratégia Saúde da Família no Nordeste Brasileiro, e procura contextualizar e refletir criticamente sobre o desenvolvimento desta no ambiente de mudanças e desafios do Sistema Único de Saúde (SUS) e da Atenção Primária à Saúde (APS) nos seus 29 anos de implementação. Foi concebido pelo grupo de pesquisadores em Saúde da Família da unidade da Fundação Oswaldo Cruz (Fiocruz) sediada no Ceará. Fortalecer e qualificar a Estratégia Saúde da Família (ESF) consiste em um dos seus objetivos institucionais, e este processo teve início há 12 anos, quando a instituição liderou o processo de criação da Rede Nordeste de Formação em Saúde da Família (RENASF), composta por 26 entidades partícipes, entre elas instituições de ensino superior e órgãos representativos do SUS. A RENASF oferta uma Pós-Graduação em Saúde da Família, com 400 mestres formados, e, com edital publicado para o Doutorado Profissional em Saúde da Família, que oportunizará a formação de pesquisadores neste domínio de conhecimentos e práticas. O Mestrado Profissional em Saúde da Família à distância (PROFSAÚDE), também está implementado na Fiocruz Ceará. Ambos os programas têm se desenvolvido em diversos estados do nordeste brasileiro, proporcionando uma capilaridade na formação stricto sensu na ESF. Esta integração com profissionais da ESF, que são mestrandos, docentes, pesquisadores e egressos desses programas, tem produzido perguntas, pesquisas e tecnologias para orientar a prática na APS. Compartilhar o conhecimento produzido por esta comunidade de práticas e aprendizagem em saúde coletiva foi um dos motivadores deste número temático.

Há 12 meses atrás, quando decidimos organizá-lo, não tínhamos dimensão da grave crise sanitária que o Brasil enfrentaria na Pandemia de COVID-19. Nesta oportunidade queremos nos solidarizar com as famílias e com os profissionais de saúde que atravessam o luto pelas 260.976 vidas perdidas no país até 04 de março de 2021, sendo 57.738 (22\%) destas no Nordeste. A ESF é hoje uma das principais portas de entrada de pessoas com COVID-19 no SUS, sendo que $89,5 \%$ dos profissionais participantes de uma pesquisa nacional reportaram adaptação dos fluxos de atendimento nas unidades para atender a casos ${ }^{1}$. Ressaltamos que a ESF é também a estrutura organizacional do SUS, por sua capilaridade, acessibilidade e vínculo com as comunidades, capaz de implementar a vigilância epidemiológica, a imunização em massa e a educação para medidas não farmacológicas de prevenção do Sars-CoV-2 nos territórios de todo o Brasil, de forma a conter a Pandemia.

Nesta edição, estão reunidos 20 artigos elaborados por cerca de 98 autores dos 09 estados nordestinos (Maranhão, Piauí, Ceará, Rio Grande do Norte, Paraíba, Pernambuco, Alagoas, Sergipe e Bahia) sobre temas atinentes à ESF e APS. Eles foram vividos/pesquisados/refletidos/escritos por médicos, enfermeiros, cirurgiões dentistas, agentes comunitários de saúde, técnicos de enfermagem e saúde bucal, profissionais dos Núcleos de Atenção em Saúde da Família, gestores, professores e pesquisadores. Tratam principalmente sobre: (1) Políticas, serviços, práticas e inovações tecnológicas na Estratégia Saúde da Família; (2) Campos de práticas profissionais, acesso ao cuidado e educação na Estratégia Saúde da Família.

São apoiadores e financiadores deste número temático a Fiocruz Ceará, a Rede de Políticas Públicas e Modelos de Atenção e Gestão de Saúde (PMA) da Vice-Presidência de Pesquisa e Coleções Biológicas (VPPCB) da Fiocruz, e a RENASF.

Antônio Carlile Holanda Lavor (https://orcid.org/0000-0002-7548-4332) ${ }^{1}$

${ }^{1}$ Fiocruz Ceará. Eusébio CE Brasil

\section{Referências}

1. Bousquat A, Giovanella L, Medina MG, Mendonça MHM, Facchini LA, Tasca R. Nedel F, Lima JG, Mota PHS, Aquino R. Desafios da Atenção Básica no enfrentamento da pandemia da Covid-19 no SUS. Relatório de Pesquisa. Rio de Janeiro: USP, Fiocruz, UFBA, UFPEL, OPAS Brasil, Rede de Pesquisa em APS Abrasco; 2020. 